\title{
CONHECER PARA CONSERVAR: ANÁLISE DA INSERÇÃO SOCIAL DO PARQUE NATURAL MUNICIPAL DO CURIÓ DE PARACAMBI-RJ
}

\author{
Larissa Pires Macedo Oliveira dos Santos ${ }^{1}$ \\ Douglas de Souza Pimentel ${ }^{2}$
}

\section{RESUMO}

A criação de Unidades de Conservação (UCs) tem sido uma das principais estratégias adotadas em resposta aos níveis insustentáveis de degradação aos quais diversos ecossistemas têm sido submetidos. Porém, apenas a delimitação dessas áreas não garante a qualidade ambiental, tampouco a concordância da população com os esforços conservacionistas. Para que os propósitos dessas instituições sejam alcançados, é preciso que seu valor seja reconhecido, sendo fundamentais pesquisas que considerem o fator humano nas questões sobre conservação. O presente estudo objetivou analisar o papel social do Parque Natural Municipal Curió de Paracambi, sob o ponto de vista conservacionista, a partir da percepção ambiental dos moradores do entorno do Parque. Foram entrevistadas 96 pessoas das quais a maioria vive no entorno do PNMC há pelo menos 15 anos. Apesar disso, constatou-se um distanciamento em relação a este e a falta de conhecimento sobre o que é uma UC. Foram identificados a atribuição de valores subjetivos ao meio natural e o reconhecimento da necessidade de ações para a conservação e do relevante papel das UCs na esfera socioambiental. Todavia, ainda há pouca integração do PNMC à sociedade, sendo recomendáveis medidas que alcancem todos os seus segmentos, inclusive aquelas que fomentem o adequado uso dos recursos, como incentivo à visitação e educação ambiental.

Palavras-chaves: Áreas Protegidas; Educação Ambiental; Papel Social dos Parques.

\begin{abstract}
Different anthropogenic activities have led ecosystems to unsustainable levels of degradation. Therefore, it is important to create strategies for conserving the environment and the institution of protected areas is one of the principal strategies adopted. However, only the delimitation of parks doesn't guarantee its protection, nor the population agreement with conservation efforts. Thus, studies that take into account the human factor in conservation issues are needed. The present study intended to analyze the social role of the Municipal Natural Park Curió de Paracambi from a conservation point of view by evaluating the environmental perception of the residents of its surroundings. It was conducted the application of forms to 96 residents. The majority lives at the neighborhoods adjacent to the Park for at least 15 years. Nevertheless, it was observed a lack of knowledge about what is a protected area and an unfamiliarity about the Park. The attribution of subjective values to the natural environment and the recognition of the need for actions for conservation and the relevant role of the conservation units in the socio-environmental sphere were also identified. However, there is still little integration of the PNMC into society. Actions to reach all its segments are

\footnotetext{
${ }^{1}$ Bacharel em Ciências Biológicas pela Universidade Federal Fluminense. Email: 1arissa_pms@ hotmail.com

${ }^{2}$ Prof. Adjunto UFF e UERJ. E-mail: douglasgeia@gmail.com
} 
recommended, including those that promote its proper resource use, as the incentive to visitation and environmental education.

Keywords: Protected Areas; Environmental Education; Social Role of Parks.

\section{INTRODUÇÃO}

A constituição federal brasileira traz em seu artigo 225 o direito ao meio ambiente ecologicamente equilibrado, incumbindo ao poder público e à sociedade sua preservação para a atual e para as futuras gerações (BRASIL, 1988). No Brasil, a criação de Unidades de Conservação (UCs) é uma das principais estratégias adotadas para a conservação da biodiversidade (BENSUSAN, 2006). Dentre as diferentes categorias de UCs existentes, encontram-se os Parques, populares por oferecerem maiores possibilidades de interação entre visitantes e natureza (DUARTE, 2011). Logo, essas áreas protegidas exercem papel social essencial, pois, além de protegerem o patrimônio ambiental, direito de todos os cidadãos, propiciam serviços ambientais, alternativas econômicas e de educação ambiental. De acordo com o art. 11 da Lei 9985 de 2000, os parques objetivam à

[...] preservação de ecossistemas naturais de grande relevância ecológica e beleza cênica, possibilitando a realização de pesquisas científicas e o desenvolvimento de atividades de educação e interpretação ambiental, de recreação em contato com a natureza e de turismo ecológico.

Dessa forma a lei evidencia que os Parques desempenham papel no ensino, recreação, aproximação com o ambiente natural e nas investigações científicas. A despeito da natureza integradora dessas instituições, um dos grandes problemas referentes à conservação ambiental é o distanciamento da população em relação ao tema (RISSO, 2009).

Melazo (2005, p. 41) estabelece que "[...] o meio ambiente e o homem tornam-se protagonistas de uma importante relação de interdependência.”. Consequentemente, as questões relacionadas ao envolvimento da população com a conservação são umas das mais discutidas e relevantes para o alcance dos objetivos das UCs. Isso se aplica especialmente aos Parques, amplamente acessíveis ao público, pois, assim como seus benefícios, os impactos negativos causados pela ação antrópica também possuem abrangência que ultrapassa suas fronteiras (EHRENFELD, 2000).

Percebe-se então que apenas a delimitação de Parques não garante a qualidade e o equilíbrio ambientais, tampouco a concordância da população com as iniciativas conservacionistas (PIMENTEL, MAGRO, SILVA-FILHO, 2013). Para a consolidação do sistema de UCs e o cumprimento de suas finalidades, é necessário que seu valor seja reconhecido, sendo fundamentais estudos que levem em conta o fator humano nas questões sobre conservação. O presente artigo relata a análise do papel social do Parque Natural Municipal Curió de Paracambi sob o ponto de vista conservacionista, a partir da avaliação da percepção ambiental dos moradores do entorno do Parque e da identificação de elementos que caracterizam ou não o alcance de seus objetivos. 


\section{MATERIAL E MÉTODOS}

\section{Área de estudo}

O Parque Natural Municipal do Curió (PNMC) localiza-se no município de Paracambi (22³5'55.6"S 4342'21.2"O), região metropolitana do Rio de Janeiro, a $80 \mathrm{~km}$ da capital (Figura 1) (ITPA, 2010).

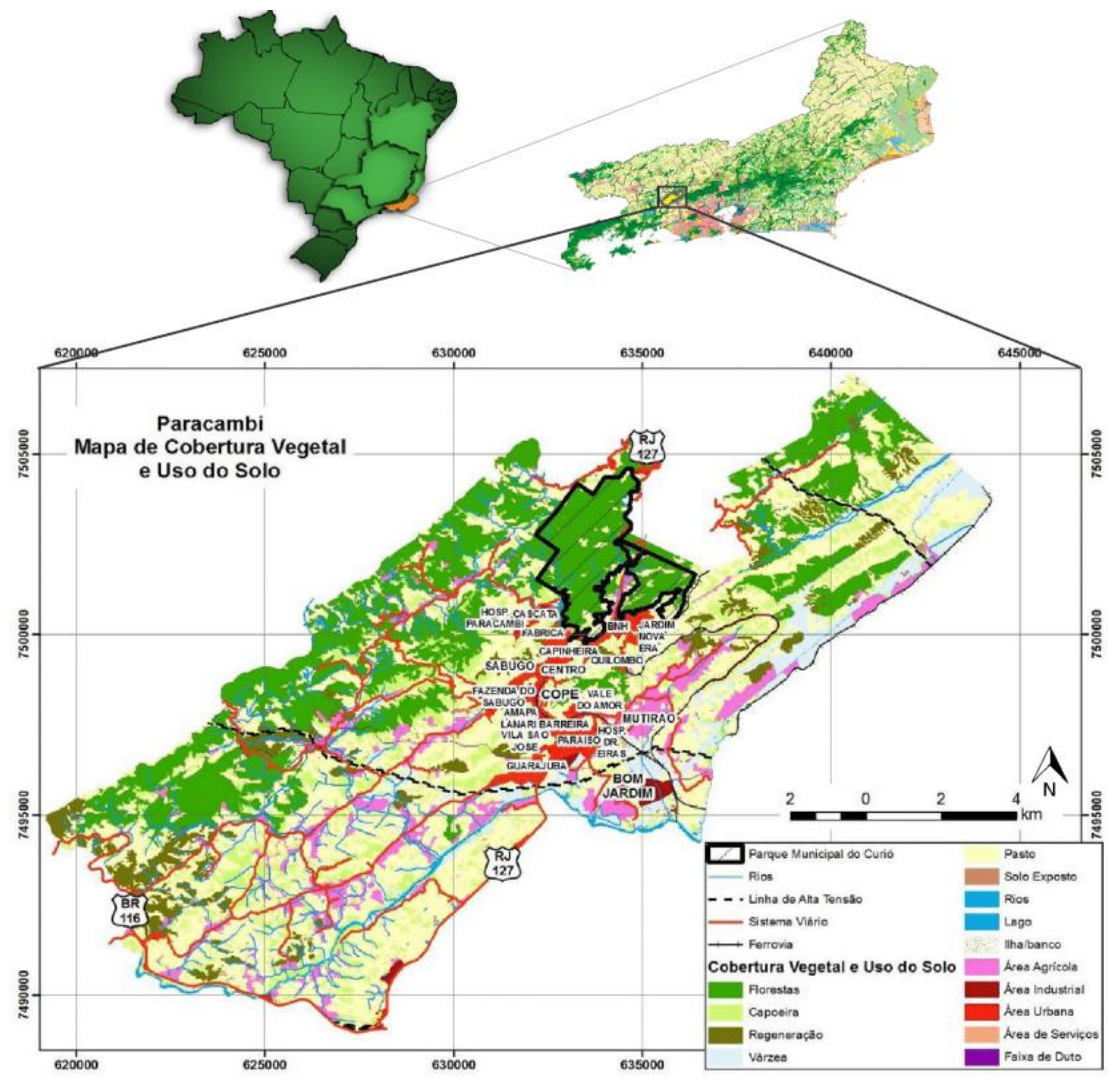

Figura 1 - Mapa do município de Paracambi (RJ) com destaque (contorno preto) para a área do PNMC (Fonte: ITPA, 2010).

Possui uma área de 913 hectares, situada no domínio da Mata Atlântica, mais precisamente nas escarpas da Serra do Mar. A UC foi criada pelo Decreto Municipal $N^{\circ} 1001$, de 29 de janeiro de 2002 para conservar a parcela florestal mais bem preservada da cidade. $\mathrm{O}$ clima é subtropical nas regiões montanhosas e tropical quente e úmido nas mais baixas. Sua vegetação é típica da Mata Atlântica, sendo classificada pelo IBGE como Floresta Ombrófila Densa. As formações são secundárias, com possíveis exceções de mata primária nas regiões mais íngremes nas encostas e no entorno de nascentes. Além da proteção florestal, o PNMC resguarda importantes afluentes do Rio dos Macacos (ITPA, 2010).

O Parque do Curió, como é conhecido, é limítrofe aos municípios de Engenheiro Paulo de Frontin e Mendes (RJ) e, no âmbito do Município de Paracambi, a dez bairros (ITPA, 2010).

\section{Os instrumentos de coleta de dados}


Para o exame do papel social da UC, foi realizada uma entrevista com um de seus dois gestores e a aplicação de formulários a moradores maiores de idade de bairros paracambienses contíguos ao Parque. Os instrumentos utilizados consistiam em uma combinação de questões abertas e fechadas e foram aplicados por dois pesquisadores entre os dias 10 de setembro e 21 de outubro de 2016. Buscou-se traçar um perfil dos moradores por meio de perguntas acerca da idade, tempo de residência no bairro, bairro ou cidade de origem e grau de escolaridade, bem como obter informações que possibilitassem a análise da percepção ambiental destes, usando questionamentos sobre seu entendimento a respeito do que é uma UC, conhecimento de UCs, visitação, realização de atividades associadas ao PNMC, discernimento sobre o Parque do Curió e opiniões a respeito de aspectos conservacionistas, como medidas de proteção deste e benefícios por ele proporcionados.

Os moradores foram abordados aleatoriamente em locais públicos, em diferentes períodos do dia. O cálculo do tamanho da amostra necessário à sua representatividade para $90 \%$ de nível de confiança e $10 \%$ de erro foi realizado de acordo com a fórmula utilizada no estudo de Pimentel (2011).

Para que o número de entrevistas fosse proporcional à quantidade de moradores de cada bairro adjacente à UC, foi feita uma estimativa da distribuição da população entre os mesmos, usando suas respectivas áreas construídas aproximadas, já que o município não dispunha desse tipo de informação, mas apenas da população total. Para a análise dos dados a área de amostragem foi tratada como um todo. Esta foi baseada principalmente na estatística descritiva, sendo as respostas às questões abertas analisadas sob a metodologia da análise de conteúdo proposta por Bardin, a qual indica categorizá-las de acordo com as atividades ou indicadores de referência (BARDIN, 2011).

Já para a obtenção de dados sobre o PNMC, no dia 11 de novembro de 2016 foi realizada uma entrevista semiestruturada com um de seus gestores, na Secretaria Municipal de Meio Ambiente e Desenvolvimento Sustentável de Paracambi (SEMADES). Esta foi gravada com um Smartphone Apple iPhone 6 e depois transferida para um arquivo no computador. Os questionamentos versaram sobre atividades, projetos e ocorrências na esfera do Parque do Curió (Tabela I) com o intuito de obter elementos para o estabelecimento de contrapontos, em uma análise subjetiva, com as respostas obtidas por meio dos formulários.

Tabela I - Questões usadas na entrevista com o gestor do PNMC.

\begin{tabular}{cl}
\hline \multicolumn{1}{c}{ Questões } \\
\hline 1 & $\begin{array}{l}\text { Na sua opinião, a população de Paracambi conhece o } \\
\text { Parque? }\end{array}$ \\
2 & Como esse conhecimento pode ser ampliado? \\
3 & $\begin{array}{l}\text { Existem ou já foram realizados projetos que integram a } \\
\text { população ao Parque? }\end{array}$ \\
4 & Qual a média de visitação do Parque? \\
5 & Quais os principais visitantes? \\
6 & Em relação a educação ambiental, há algum projeto?
\end{tabular}


7 Há documentação ou relatos de incidentes que prejudicam a integridade do Parque?

8 Quais os principais problemas que prejudicam o

Parque?

9 Como se dá a relação entre a gestão e os moradores e outros interessados?

\section{RESULTADOS E DISCUSSÃO}

Foram entrevistadas 96 pessoas com idades entre dezoito e oitenta anos. Dos entrevistados, 70,8\% moram nos bairros do entorno do PNMC há pelo menos 15 anos. Apesar disso, os resultados da pesquisa apontaram para fracas relações e discernimento sobre o PNMC.

A tabela II apresenta as respostas às partes fechadas de cinco questões constantes do formulário.

Tabela II - Percentual de respostas a cinco das questões fechadas do formulário do estudo sobre o PNMC.

\begin{tabular}{|c|c|c|c|c|c|}
\hline & \multicolumn{2}{|c|}{ Questões } & \multirow[b]{2}{*}{6} & \multirow[b]{2}{*}{7} & \multirow[b]{2}{*}{8} \\
\hline & 1 & 5 & & & \\
\hline Não & $\begin{array}{l}59 \\
(61 \%)\end{array}$ & $\begin{array}{l}73 \\
(76 \%)\end{array}$ & $\begin{array}{l}79 \\
(82 \%)\end{array}$ & $\begin{array}{l}11 \\
(11 \%)\end{array}$ & $\begin{array}{l}83 \\
(86 \%)\end{array}$ \\
\hline Sim & $\begin{array}{l}37 \\
(39 \%)\end{array}$ & $\begin{array}{l}23 \\
(24 \%)\end{array}$ & $\begin{array}{l}17 \\
(18 \%)\end{array}$ & $\begin{array}{l}85 \\
(89 \%)\end{array}$ & $\begin{array}{l}13 \\
(14 \%)\end{array}$ \\
\hline
\end{tabular}

1-Você sabe o que é uma Unidade de Conservação (UC)?; 5-Você já foi ao Parque do Curió?; 6-Você já fez qualquer outra atividade relacionada ao Parque Natural Municipal Curió de Paracambi?; 7-Há algo de bom em morar próximo ao Parque?; 8-Há algo de ruim em morar próximo ao Parque?

Quando questionados se sabiam o que era uma UC, somente 39\% dos entrevistados responderam afirmativamente. Desse número, somente uma parcela de $35,1 \%$ forneceu definições mais condizentes com o conceito, englobadas na categoria "local para conservação e/ou proteção do meio ambiente e de seus elementos". Para outros, as UCs se resumem a "ações em prol da conservação, manutenção e proteção do meio ambiente e da natureza" (29,7\%). Definições genéricas utilizando o termo "conservação" totalizaram 18,9\%, enquanto "outras", 16,2\%.

Esses dados revelam a dificuldade da população em definir o que são UCs, mostrando que aqueles que afirmaram saber, são em menor número. Apesar de associarem as unidades a atividades de defesa e controle ambiental, muitos entrevistados não as distinguem nitidamente como áreas delimitadas sob regime especial de proteção, cujo objetivo maior é a conservação do meio ambiente. Em concordância, tem-se o pequeno número de respostas que condisseram com o conceito de um "local para a conservação do meio", o que reafirma uma falta de 
clareza a respeito da figura dessas instituições.

As questões 2, 3 e 4, por abarcarem objetos de estudo similares, foram reunidas para comparação (Figuras 2a, 2b, 2c), sendo dispostas de forma a investigar o quanto o PNMC é representativo e reconhecido pela população como uma Unidade de Conservação. Em um primeiro momento, 69\% $(\mathrm{n}=66)$ dos entrevistados afirmaram conhecer alguma UC, porém grande parte destes $(n=41,55 \%)$ indicou locais que não se enquadravam no conceito, representados no gráfico pelas categorias "Associado ao PNMC", “Zoo, Jardins e Outros" e "Outros", enquanto 45\% (n=33) apontaram explicitamente categorias pertencentes ao SNUC, dentre as quais o Parque do Curió (Figura 2a). Depois, dentre aqueles 52\% que disseram conhecer alguma UC próxima à cidade, 21 (41\%) indicaram o PNMC (Figura 2b), revelando um aumento de menções do Parque estudado quando comparado à questão supracitada. $\mathrm{Na}$ quarta questão, antes de os pesquisadores apresentarem o Parque do Curió, menos da metade dos entrevistados $(n=44,46 \%)$ mostraram conhecê-lo, sendo seu nome apontado na maioria das citações (84\%) (Figura 2c). Após este ser mencionado pelos pesquisadores, a proporção de entrevistados que o reconheceram aumentou consideravelmente, chegando a 80,2\% $(n=77)$.

\section{2a Conhece Alguma UC?}

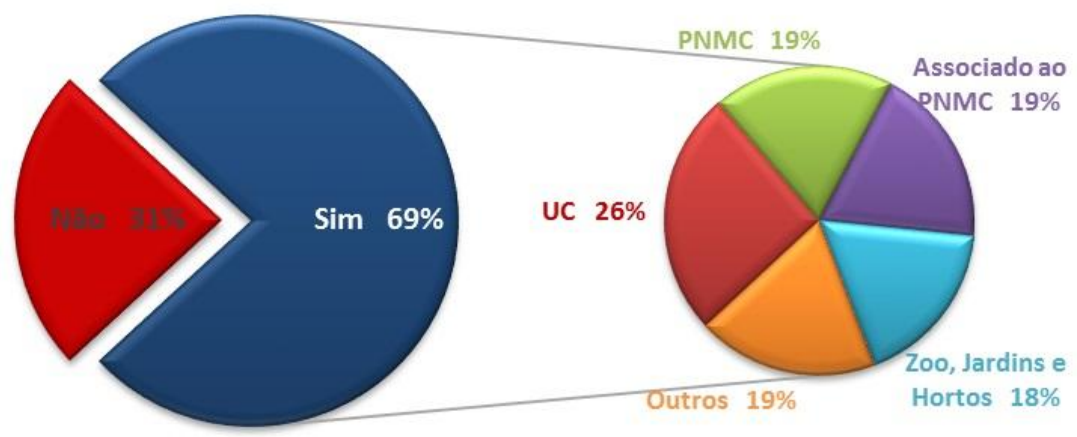

2b Conhece Alguma UC Próxima?

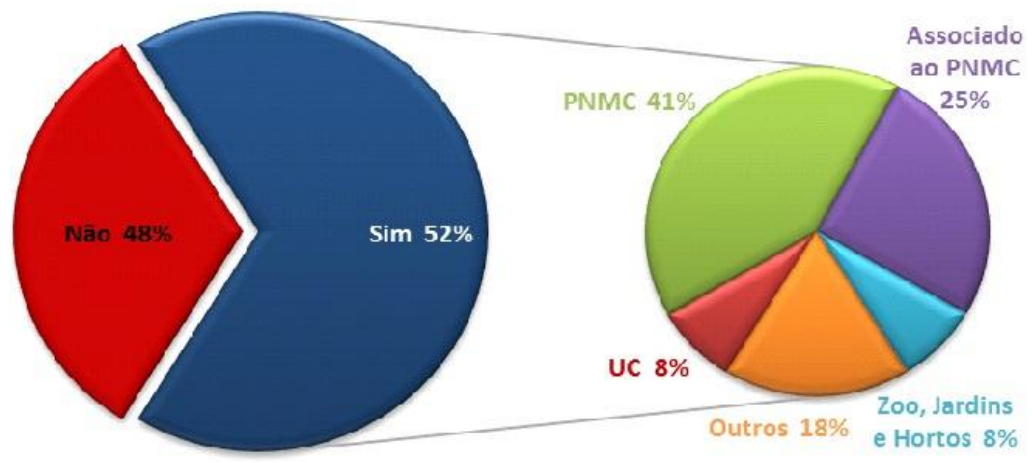




\section{2c Sabe da Existência de um Parque na} Cidade?

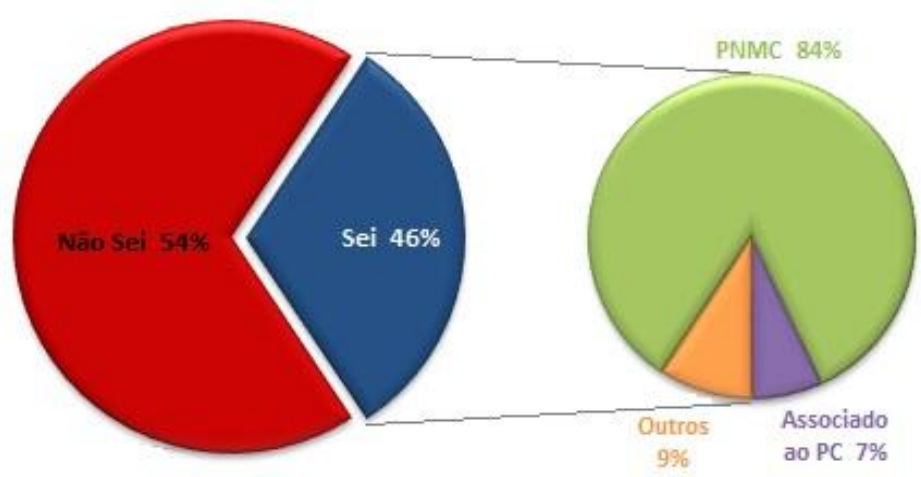

Figura 2 - Respostas às questões 2 (2a), 3 (2b) e 4 (3c) do formulário mostrando as percentagens de conhecimento de UCs e as categorias e exemplos apontados pelos entrevistados ( $n=96)$. A categoria "Associado ao PNMC" engloba respostas que não o indicaram explicitamente, mas que são associadas a este, como referências de localização.

Esse conjunto de respostas deixou transparecer que são necessárias mais informações sobre o Parque do Curió. Apesar de majoritariamente os entrevistados declararem que conheciam alguma UC ou UC próxima, menos da metade citou o PNMC, um resultado interessante, já que este se localiza no próprio Município. Esse padrão só se desfez na quarta questão, onde $84 \%$ dos respondentes o citaram. A verificação de que as menções ao PNMC aumentaram conforme as perguntas iam sendo direcionadas para isso, somada ao fato de uma parcela expressiva da população só o discernir após ser explicitamente apontado pelos pesquisadores, pode ser associada a um baixo conhecimento e apropriação do Parque por parte da comunidade, o que foi visto já à época da elaboração do Plano de Manejo, no qual se registrou que "De forma geral, os moradores do entorno sequer sabem da existência da UC, mesmo aqueles que moram dentro da área aqui proposta como ZA." (ITPA, 2010). Problema que ainda persiste.

Pimentel e Magro (2012b) propuseram em seu trabalho alguns indicadores importantes para mensuração da inserção social dos parques, dentre os quais o conhecimento da população sobre as ações da gestão, a compreensão dos problemas do Parque, a troca de experiências e o respeito e compreensão da territorialidade do Parque, identificada como deficiente no presente estudo, já que a maioria dos entrevistados relatou não conhecer os limites do PNMC.

Os resultados supracitados reforçam a necessidade, tanto de programas de educação ambiental e conscientização da população sobre o que realmente são UCs, suas características e o papel que desempenham, quanto de uma maior divulgação do PNMC. Os autores Bento e Marques (2007 e SILVA e SILVA (2013) se depararam com cenários parecidos em trabalhos sobre percepção ambiental realizados nas cidades de Uberlândia (MG) e Magé (RJ), respectivamente, nos quais também registraram baixo nível de conhecimento acerca da existência das UCs avaliadas e, no segundo caso, acerca de UCs em geral.

Percebe-se que o não reconhecimento destas, até por aqueles que vivem próximos, não é 
algo incomum, indicando que a carência de iniciativas para sensibilizar a população sobre o tema não é um problema exclusivo da região do presente estudo. A própria gestão demonstra saber da limitação do conhecimento da população acerca do PNMC e aponta a criação da sede como um meio para que o mesmo seja ampliado (informação verbal) ${ }^{3}$.

A visitação foi um fator pouco identificado na pesquisa. Apenas 23 pessoas (24\%) afirmaram já terem ido ao PNMC, o que pode ser explicado pelo fato de os principais visitantes do Parque atualmente serem pesquisadores, como alunos de iniciação científica, graduação e pós-graduação, que utilizam a área para seus estudos (informação verbal) ${ }^{4}$. Esse achado contrasta com o trabalho de Pimentel (2011), no qual a maioria dos pesquisados já havia visitado a UC estudada, o Parque Estadual da Serra da Tiririca (PESET) (Niterói/RJ), um Parque localizado no litoral, com apelo turístico, sede e centro para recepção de visitantes. Tais características justificariam a diferença entre os níveis de visitas desta e do PNMC, que ainda não possui infraestrutura para esse fim e também não tem turismo associado (ITPA, 2010).

Além disso, o Parque dispõe de poucos atrativos turísticos, abrigando seis trilhas (Trilha do Jequitibá Rosa, Trilha do Grotão-Tairetá, Trilha da Bica do Costa, Trilha do Bugio, Caminho dos Escravos ou Trilha do Açude e Trilha da Cachoeira do Pacheco) e algumas cachoeiras, mas que perdem seu potencial devido à má qualidade das águas. Concordantemente tem-se uma baixa visitação e a inexistência de turismo formal (ITPA, 2010),

Espera-se superar algumas dessas barreiras a partir da criação da sede administrativa do PNMC, um projeto que compreende atividades que aproximam o visitante da natureza, como arborismo e uma sala para educação ambiental onde serão abordadas questões relativas aos recursos naturais existentes na UC, inclusive espécies endêmicas, informando a população e aumentando seu conhecimento sobre o Parque (informação verbal) ${ }^{5}$.

Muitas vezes os moradores tomaram conhecimento da Unidade de maneira informal, através de amigos ou parentes. Dentre os que sabiam de sua existência, 44\% ( $n=41)$ foram informados através de comentários em geral ou indicaram um "saber comum" da população. Isso evidencia a importância da visitação, pois, a partir das pessoas que vão às UCs, o conhecimento acerca delas pode ser disseminado. O incentivo à visitação é importante para que a população conheça o PNMC. Além disso, seu plano de manejo, documento que o distingue, já que a maioria das UCS brasileiras não possui tal instrumento (FIGUEIREDO, 2011), indica que propiciar essa prática deve ser um dos objetivos do Parque do Curió (ITPA, 2010).

Entretanto, é sabido que o turismo pode ocasionar impactos ambientais indesejados. Nesse sentido, educação ambiental é essencial para evita-los, pois de acordo com Vasconcellos (2006), pode amenizar os potenciais impactos negativos da visitação através da

\footnotetext{
${ }^{3}$ Entrevista concedida pelo gestor do PNMC. Entrevista. [nov. 2016]. Entrevistador: Larissa Pires M. O. dos Santos. Paracambi, 2016. 1 arquivo .m4a (11 min. $37 \mathrm{~s})$.

${ }^{4} \mathrm{Id}$.

${ }^{5}$ Id.
} 
sensibilização e valorização ambiental dos visitantes.

As placas de informação na cidade constituíram o segundo maior meio de difusão da existência da UC $(n=18,19 \%)$. Uma fração de $7 \%(n=7)$ soube da instituição do Parque do Curió por intermédio de outras ações de divulgação da prefeitura e de políticos, enquanto $12 \%$ $(\mathrm{n}=11)$, por meio de atividades escolares. Uma fração reduzida (18\%) dos entrevistados disse já ter se envolvido em outras atividades associadas ao Parque, sendo as principais atividades indicadas aquelas relacionadas ao meio escolar e projetos (50\%), bem como a ações de divulgação (25\%). Os dados ressaltam a importância das referidas instituições de ensino e reforçam a ideia de que a administração poderia prestar maior atenção à execução de ações para a aproximação e a integração da UC com os demais segmentos da comunidade.

As opiniões em relação à existência de aspectos positivos de se morar nas cercanias do Parque foram predominantemente afirmativas (89\%), o que foi corroborado pela proporção de $86 \%$ de entrevistados que não identificaram malefícios decorrentes dessa condição. A valorização da natureza foi explicitada através das diversas respostas que formaram as categorias referentes ao contato com a mesma, aos animais e à conservação. A saúde e o bemestar humanos também foram abordados, principalmente por meio da grande quantidade de falas que indicaram a qualidade do ar como benefício.

Percebeu-se a atribuição de valores subjetivos ao meio natural e seus componentes e o reconhecimento de sua contribuição para uma melhor qualidade de vida. Por outro lado, não foram indicadas muitas respostas referentes explicitamente ao lazer, turismo e geração de emprego e renda. Tal fato contrasta com a pesquisa de Silva e Silva (2013), na qual se percebeu maior foco dos moradores nos referidos aspectos do que nos relacionados à proteção ambiental. Essa divergência pode estar atrelada à ausência de perspectiva, em grande parte dos moradores, de ganhos a partir da exploração turística do Parque do Curió, tanto devido ao grande desconhecimento da UC, quanto ao fato de ainda não existirem atividades com tal fim (ITPA, 2010).

A respeito dos possíveis malefícios, além da proximidade de animais (33,3\%), foram indicados pontos como a má conservação $(26,7 \%)$ e as queimadas $(20 \%)$, porém em pequeno número, por serem referentes apenas à parcela de entrevistados que identificaram pontos negativos. As queimadas, além da captura de animais e desmatamento, são realmente problemas enfrentados pela UC, embora as ocorrências não sejam frequentes (informação verbal $)^{6}$. A identificação destas ameaças aponta para a existência da percepção dos moradores acerca dessas questões que, além de afetarem o entorno, podem levar à degradação e à destruição do PNMC, o que mostra que apesar da falta de conhecimento mais específico sobre as UCs, os moradores conhecem o que deve ser evitado, um ponto positivo, se acompanhado de atitudes proativas.

Quando indagados sobre a importância de diferentes funções dos Parques, a população em geral atribuiu altas notas para todas elas, reconhecendo a necessidade de ações para a conservação do meio ambiente e, principalmente, o relevante papel dessa categoria de UC na

${ }^{6}$ Id. 
esfera socioambiental. A maior média $(9,83)$, atribuída à proteção de espécies animais e vegetais, foi a que apresentou o menor desvio padrão, demonstrando que a população concorda fortemente sobre o valor de se manter a diversidade de espécies.

Pode-se notar que a comunidade analisada percebe e concorda com a necessidade da conservação ambiental, o que também foi observado nos estudos para a elaboração do Plano de Manejo, no qual os entrevistados defenderam a importância de proteger as florestas ainda existentes na cidade, confirmando a relevância do Parque para a conservação (ITPA, 2010). Impressão semelhante tem-se a partir da décima questão, na qual a grande maioria concordou com o fato de a UC beneficiar a cidade, provavelmente se referindo à esfera ambiental, pois não existem ganhos perceptíveis no âmbito socioeconômico atribuídos ao Parque.

$\mathrm{Na}$ supracitada questão ainda se notam outros pontos a serem avaliados. Apesar de a maior parte dos voluntários concordarem com quase todas as afirmativas, houve uma pequena discordância e maior número de posicionamentos indiferentes quanto à capacidade do Parque de influenciar o comportamento dos moradores. Isto sugere que o PNMC poderia ser melhor utilizado para educação ambiental e para influenciar novas atitudes na comunidade em relação ao meio ambiente.

\section{CONSIDERAÇÕES FINAIS}

Uma grande parcela dos entrevistados apenas tinha ouvido falar do Parque do Curió, não detendo maiores informações, sendo poucos os registros de atividades associadas ao mesmo, como a visitação. Porém, mesmo com a falta de conhecimento mais formal sobre o tema, os moradores demonstraram ter consciência da importância da conservação ambiental e da contribuição da UC para isso. Ademais, foi registrada a percepção de moradores acerca de problemas associados ao PNMC, um resultado positivo de acordo com os indicadores de inserção social.

As funções do Parque relacionadas à esfera social propriamente dita, como educação ambiental, pesquisa, recreação e turismo foram pouco observadas nas respostas dos moradores. Mesmo com a realização de atividades de educação ambiental, a exemplo do Programa de Conservação da Mata Atlântica realizado em 2008 e 2011 e de divulgação por parte da gestão (informação verbal) ${ }^{7}$, essas se mostraram como projetos pontuais e que poderiam ser mais difundidos. É recomendável que haja maior diálogo e integração entre a população local e a gestão da UC para que as ações realizadas por esta sejam conhecidas pela sociedade e ocorra maior troca de experiências entre esses dois atores.

Percebeu-se também uma carência de conhecimento da população em relação a UCs em geral e, mais especificamente, ao PNMC. Apesar das deficiências da atuação da gestão da UC, foram também registrados pontos positivos como seu bom estado de conservação (ITPA, 2010) e o fato de possuir Plano de Manejo, um diferencial, já que a maioria das UCs brasileiras não possui tal documento.

${ }^{7}$ Id. 
Contudo, há ainda pouca integração do PNMC à sociedade, ator que tem maior potencial para modificações do ambiente. Para melhorar esse cenário são recomendáveis medidas que alcancem todos os seus segmentos, como incentivo à visitação, aperfeiçoamento e intensificação dos trabalhos com escolas, importantes divulgadoras da UC, educação ambiental, divulgação, e aproveitamento de seu potencial turístico, educacional e recreativo, buscando-se, dessa forma, o cumprimento integral das atribuições do Parque do Curió.

\section{REFERÊNCIAS BIBLIOGRÁFICAS}

BARDIN, L. ANÁLISE DE CONTEÚDO. 1. ed. São Paulo: EDIÇOES 70 - BRASIL, 2011. BENSUSAN, N. Conservação da biodivesrsidade em áreas protegidas. Rio de Janeiro: Editora FGV, 2006.

BENTO, L. C. M.; MARQUES, V. A. S. O PARQUE MUNICIPAL SANTA LUZIA NA ÓTICA DOS MORADORES DOS BAIRROS PAMPULHA E SANTA LUZIA, UBERLÂNDIA/MG. GEOAMBIENTE ON-LINE - Revista Eletrônica do Curso de Geografia do Campus Jataí UFG, Jataí, N.9 (2007). Disponível em: <http://revistas.jatai.ufg .br/geoambiente/article/view/25944>. Acesso em: 4 nov. 2016.

BRASIL.CONSTITUIÇÃO (1988). CONSTITUIÇÃO DA REPÚBLICA FEDERATIVA DO BRASIL. Brasília, DF: Senado Federal.

BRASIL. LEI No 9.985, DE 18 DE JULHO DE 2000. Regulamenta o art. 225, § 1o, incisos I, II, III e VII da Constituição Federal, institui o Sistema Nacional de Unidades de Conservação da Natureza e dá outras providências. Diário Oficial [da] República Federativa do Brasil, Brasília, DF, 19 jul. 2000.

DUARTE, A. E. M. O SISTEMA NACIONAL DE UNIDADES DE CONSERVAÇÃO DA NATUREZA. [s. 1]: Ministério do Meio Ambiente, [2011].

EHRENFELD, D. War and peace and conservation biology. Conservation Biology, Washington, v. 14, n. 1, p. 105-112, 2000.

FIGUEIREDO, L. V. R. Percepção ambiental em uma unidade de conservação de proteção integral. 2011. 177 f. Dissertação (Mestrado em Desenvolvimento Social) Universidade Estadual de Montes Claros, Montes Claros.

GESTOR. Entrevista. Nov. 2016. Entrevistador: Larissa Pires M. O. dos Santos. Paracambi, 2016. 1 arquivo .m4a (11 min. $37 \mathrm{~s})$.

ITPA-INSTITUTO TERRA DE PRESERVAÇÃO AMBIENTAL. Plano de Manejo do Parque Natural Municipal Curió de Paracambi. [Paracambi], 2010. Disponível em: <http://www.itpa.org.br/?page_id=474>. Acesso em: 17 jun. 2016.

MELAZO, G. C. PERCEPÇÃO AMBIENTAL E EDUCAÇÃO AMBIENTAL: UMA REFLEXÃO SOBRE AS RELAÇÕES INTERPESSOAIS E AMBIENTAIS NO ESPAÇO URBANO. Olhares \& Trilhas, Uberlândia, Ano VI, n. 6, p. 45-51, 2005. 
PARACAMBI. DECRETO $\mathbf{N}^{\circ} 1001$ DE 29 JANEIRO DE 2002. Cria O PARQUE MUNICIPAL CURIÓ DE PARACAMBI, e dá outras providências. Jornal Hora H. 2 fev. 2002. Disponível em: <https://ecozone.files.wordpress.com/2014/07/lei-1001-2002-criaparque.pdf>. Acesso em: 31 dez. 2016.

PIMENTEL, Douglas de Souza; MAGRO, Teresa Cristina. Indicadores para a gestão da inserção social de parques. Olam: Ciência \& Tecnologia (Rio Claro. Online), v. XII, p. 254277, 2012 b.

PIMENTEL, Douglas de Souza; MAGRO, Teresa Cristina ; SILVA FILHO, D. F. . Imagens da Conservação: Em busca do apoio público para a gestão de Unidades de Conservação. Teoria \& Sociedade (UFMG), v. 19, p. 144-168, 2013.

PIMENTEL, Douglas de Souza; MAGRO, Teresa Cristina . The symbolic sphere and social representations of Serra da Tiririca State Park, Rio de Janeiro, Brazil. Sociedade \& Natureza (UFU. Online), v. 23, p. 275-283, 2011.

RISSO, L C. ESTUDO DE PERCEPÇÃO E CONSERVAÇÃO DO PARQUE ECOLÓGICO DE OURINHOS-SP: discussões a respeito da percepção e metodologia. In: XIII Simpósio Brasileiro de Geografia Física Aplicada, 2009, Anais... Viçosa - MG. A Geografia física e as dinâmicas de apropriação da Natureza. Viçosa: Cópias e Cópias, 2009. v. 1. p. 1-18.

SILVA, V. M. da; SILVA, B. T. B. da. PERCEPÇÃO AMBIENTAL DA COMUNIDADE DO ENTORNO DO PARQUE NATURAL MUNICIPAL BARÃO DE MAUÁ, MUNICÍPIO DE MAGÉ, RJ. In: Uso Público em Unidades de Conservação, n. 1, v. 1, 2013. Anais... Niterói. Anais... Niterói: UFF, 2013. p. 200-210.

VASCONCELLOS, J.M. Educação e interpretação ambiental em unidades de conservação. Coleção Cadernos de Conservação v. 3, n. 4. Curitiba: Fundação o Boticário de Proteção à Natureza, 2006. 86p. 